\title{
Halomonas stevensii sp. nov., Halomonas hamiltonii sp. nov. and Halomonas johnsoniae sp. nov., isolated from a renal care centre
}

Correspondence

Jung-Sook Lee

jslee@kribb.re.kr

\author{
Kwang Kyu Kim, Keun Chul Lee, Hee-Mock Oh and Jung-Sook Lee
}

Korean Collection for Type Cultures, Biological Resource Center, Korea Research Institute of Bioscience and Biotechnology, 52 Eoeun-dong, Yuseong-gu, Daejeon 305-806, Republic of Korea
The family Halomonadaceae of the class Gammaproteobacteria currently comprises ten genera, Carnimonas, Chromohalobacter, Cobetia, Halomonas, Halotalea, Kushneria, Modicisalibacter, Salicola, Salinicola and Zymobacter, which accommodate halophilic/halotolerant and non-halophilic bacteria. Since the family Halomonadaceae was first described (Franzmann et al., 1988), its members typically have occurred in saline lakes, solar salt facilities, saline soils and marine environments. Since some of its members are also alkaliphilic, they are found in soda lakes and alkaline soils. The exceptions to the above are Carnimonas nigrificans, Chromohalobacter beijerinckii, Chromohalobacter canadensis, Chromohalobacter japonicus, Halomonas alimentaria, Halomonas alkaliphila, Halomonas campaniensis, Halomonas daqingensis, Halomonas desiderata, Halomonas halodenitrificans, Halomonas muralis, Halotalea alkalilenta, Kushneria aurantia, Kushneria avicenniae, Modicisalibacter tunisiensis and Zymobacter palmae

\footnotetext{
Abbreviations: EPS, exopolysaccharide; PHB, poly- $\beta$-hydroxybutyrate.

The GenBank/EMBL/DDBJ accession numbers for the 16S rRNA gene sequences of Halomonas stevensii $\mathrm{S} 18214^{\top}$, Halomonas hamiltonii $\mathrm{W}_{1025^{\top}}$ and Halomonas johnsoniae $\mathrm{T} 68687^{\top}$ are AM941388, AM941396 and AM941399, respectively.

A neighbour-joining phylogenetic tree based on 16S rRNA gene sequences showing the positions of the novel Halomonas strains among all described Halomonas species (Fig. S1), and DNA-DNA hybridization data (Table S1) and fatty acid contents of cells grown on TSA with $5 \%$ $\mathrm{NaCl}$ (Table S2) of the novel strains and closely related Halomonas type strains are available with the online version of this paper.
}

(Arahal \& Ventosa, 2006; Ben Ali Gam et al., 2007; Ntougias et al., 2007; Peçonek et al., 2006; Romano et al., 2005, 2006; Sánchez-Porro et al., 2007, 2009; Wu et al., 2008). Of these 16 organisms, only Zymobacter palmae is neither halophilic nor halotolerant.

Members of the genus Halomonas are ubiquitous and moderately halophilic/halotolerant bacteria and, at the time of writing, the genus comprised 56 phylogenetically heterogeneous species. The type species is Halomonas elongata. During the screening of bacteria from patients who developed bacteraemia during dialysis and from dialysis machines, 14 halophilic organisms were isolated, which were considered to belong to novel species in the genus Halomonas, and subjected to a polyphasic taxonomic investigation.

Strains $\mathrm{S}_{18214^{\mathrm{T}}}$ and T49407 were isolated from the blood of two patients and strains F22135, F22157, F22171, H35115, T68674, T68679, T68687 ${ }^{\mathrm{T}}$, W1012, W1017, $\mathrm{W} 1019, \mathrm{~W} 1023$ and $\mathrm{W} 1025^{\mathrm{T}}$ were isolated from dialysis machines of a renal care centre in Santa Clara Valley Medical Center, San Jose, California, USA (Stevens et al., 2008). For most experiments, strains were cultured on solid MH medium (Ventosa et al., 1982) with $5 \%(\mathrm{w} / \mathrm{v})$ sea-salt solution (Rodríguez-Valera et al., 1981) at $30{ }^{\circ} \mathrm{C}$ for $48 \mathrm{~h}$. When strains were cultured on other complex media for phenotypic tests, the final salt concentration was adjusted to $5 \%(\mathrm{w} / \mathrm{v})$ according to the above. For fatty acid analysis, strains were cultured on tryptic soy agar (TSA; Difco) and on TSA with $5 \%(\mathrm{w} / \mathrm{v}) \mathrm{NaCl}$ at $30{ }^{\circ} \mathrm{C}$ for $48 \mathrm{~h}$. Halomonas 
aquamarina KCTC $22913^{\mathrm{T}}$, Halomonas axialensis KCTC $22914^{\mathrm{T}}$, Halomonas magadiensis KCTC $22915^{\mathrm{T}}$ and Halomonas meridiana KCTC $22916^{\mathrm{T}}$, grown under identical conditions, were used as reference strains for fatty acid analysis, other phenotypic tests and DNA-DNA hybridization tests.

The Gram reaction was performed as described by Gerhardt et al. (1994). Cell morphology and motility were observed under a light microscope (Optiphot-2, Nikon; $\times 1500$ magnification) with cells grown for 1-7 days. Motility was tested by the hanging-drop technique (Skerman, 1967) and the presence of flagella was determined by transmission electron microscopy (JEM1011; JEOL) after negative staining with $2 \%(\mathrm{w} / \mathrm{v})$ uranyl acetate. Poly- $\beta$-hydroxybutyrate (PHB) staining was done in 5 day cultures by using the method of Ostle \& Holt (1982). Exopolysaccharide (EPS) production was examined on solid MH medium after incubation for 3 days (Mata et al., 2002). Oxidase activity was tested by using BactidentOxidase strips (Merck) and catalase activity was tested by using $3 \% \mathrm{H}_{2} \mathrm{O}_{2}$. Growth was investigated at temperatures ranging from 5 to $50{ }^{\circ} \mathrm{C}$ at intervals of $5{ }^{\circ} \mathrm{C}$ and at $\mathrm{pH} 5-11$ at intervals of $1 \mathrm{pH}$ unit. Requirement for and tolerance of salts were determined in liquid $\mathrm{MH}$ medium with different sea-salt concentrations $(0,0.5,1,2,3,5,7.5,10,15,20,25$ and $30 \%, w / v)$. Anaerobic growth was examined on solid MH medium incubated in jars with the GasPak anaerobic system (BBL). Growth on MacConkey agar (Difco) and cetrimide agar (Difco) was investigated. Hydrolysis of casein, DNA, starch and tyrosine was tested on casein agar (Difco), DNase test agar (BBL), starch agar (Difco) and tyrosine agar (PML Microbiologicals). Hydrolysis of Tween 20 and Tween 80 was tested on solid MH medium supplemented with $1 \%(\mathrm{v} / \mathrm{v})$ Tween 20 or Tween 80 . Haemolysis was studied on solid MH medium supplemented with $5 \%(\mathrm{v} / \mathrm{v})$ sheep blood. The lecithovitellin test was performed on egg yolk agar (McClung \& Toabe, 1947). Utilization of glucose by oxidation or fermentation was checked in modified MOF medium (Ventosa et al., 1982) with $5 \%(\mathrm{w} / \mathrm{v}) \mathrm{NaCl}$. Respiration on nitrate, nitrite and fumarate, selenite reduction and gluconate oxidation were studied according to the procedures of Mata et al. (2002). $\mathrm{H}_{2} \mathrm{~S}$ production was tested in liquid $\mathrm{MH}$ medium supplemented with $0.01 \%(\mathrm{w} / \mathrm{v})$ cysteine with a strip of lead acetate paper (Fluka) as an indicator. Methyl red and Voges-Proskauer tests were performed in MR-VP broth (BBL). A nutritional assay was carried out using modified Koser medium (Ventosa et al., 1982) containing (\%, w/v): $\mathrm{NaCl}, \quad 5 ; \mathrm{KCl}, 0.2 ; \mathrm{MgSO}_{4} .7 \mathrm{H}_{2} \mathrm{O}, 0.02 ; \mathrm{KNO}_{3}, 0.1 ;$ $\left(\mathrm{NH}_{4}\right)_{2} \mathrm{HPO}_{4}, 0.1 ; \mathrm{KH}_{2} \mathrm{PO}_{4}, 0.05$. Filter-sterilized substrate $(0.1 \%, \mathrm{w} / \mathrm{v})$ was added to this medium, with the exception of carbohydrates, which were used at $0.2 \%(\mathrm{w} / \mathrm{v})$. When amino acids were used as substrates, the basal medium contained neither $\mathrm{KNO}_{3}$ nor $\left(\mathrm{NH}_{4}\right)_{2} \mathrm{HPO}_{4}$. The organic compounds tested as sole sources of carbon and energy or sole sources of carbon, nitrogen and energy were as follows: aesculin, amygdalin, glycogen, L-arabinose, cellobiose, D- fructose, D-fucose, D-galactose, D-glucose, lactose, maltose, D-mannose, melezitose, raffinose, L-rhamnose, D-ribose, Dsalicin, starch, sucrose, trehalose, D-xylose, adonitol, dulcitol, ethanol, glycerol, myo-inositol, D-mannitol, sorbitol, acetate, adipate, citrate, formate, fumarate, gluconate, 3-hydroxybenzoate, 4-hydroxybenzoate, malate, malonate, propionate, succinate, L-alanine, L-cysteine, L-histidine, DLisoleucine, L-lysine, L-methionine, L-proline, L-serine and L-valine. Acid production tests, enzyme activity tests and additional phenotypic tests were performed by using API 20E, API 20NE, API 50CH and API ZYM galleries according to the instructions of the manufacturer (bioMérieux); the inocula for API test kits were supplemented with $5 \%(\mathrm{w} / \mathrm{v})$ sea-salt solution. Duplicate antibiotic susceptibility tests were performed by using Sensi-Discs (6 mm; BBL) containing the following: amoxicillin $(25 \mu \mathrm{g})$, ampicillin $(10 \mu \mathrm{g})$, carbenicillin $(100 \mu \mathrm{g})$, cefoxitin $(30 \mu \mathrm{g})$, cefotaxime $(30 \mu \mathrm{g})$, chloramphenicol $(30 \mu \mathrm{g})$, erythromycin $(15 \mu \mathrm{g})$, kanamycin $(30 \mu \mathrm{g})$, nalidixic acid $(30 \mu \mathrm{g})$, neomycin $(30 \mu \mathrm{g})$, nitrofurantoin $(300 \mu \mathrm{g})$, penicillin $\mathrm{G}(10 \mathrm{IU})$, polymyxin $\mathrm{B}$ (300 IU), rifampicin $(5 \mu \mathrm{g})$, streptomycin $(10 \mu \mathrm{g})$, sulphamide $(250 \mu \mathrm{g})$, tetracycline $(30 \mu \mathrm{g})$, tobramycin $(10 \mu \mathrm{g})$, trimethoprim/sulfamethoxazole $(1.25 \mu \mathrm{g} / 23.75 \mu \mathrm{g})$ and vancomycin $(30 \mu \mathrm{g})$. Zone diameter interpretive standards of the NCCLS (2003) were used for interpretation.

Fatty acid methyl esters were prepared and analysed as described by Klatte et al. (1994) by using the standard Microbial Identification System (MIDI) for automated GC analysis (Sasser, 1990; Kämpfer \& Kroppenstedt, 1996). Isoprenoid quinones were extracted with chloroform/ methanol $(2: 1, \mathrm{v} / \mathrm{v})$ and purified by using TLC on Kieselgel $60 \mathrm{~F}_{254}$ plates $(20 \times 20 \mathrm{~cm}, 0.5 \mathrm{~mm}$ thickness; Merck) with petroleum ether/diethyl ether $(9: 1, \mathrm{v} / \mathrm{v})$ as the solvent. The identities of the quinones were determined by using reversed-phase HPLC analysis as described by Shin et al. (1996).

Extraction of genomic DNA, PCR-mediated amplification of the 16S rRNA genes and sequencing of purified PCR products were carried out according to Rainey et al. (1996). The 16S rRNA gene sequences were aligned with published sequences retrieved from GenBank/EMBL/DDBJ by using CLUSTAL_X (Thompson et al., 1997) and edited via the BIOEDIT program (Hall, 1999). Phylogenetic trees were constructed on the basis of the neighbour-joining (Saitou \& Nei, 1987) and maximum-parsimony (Fitch, 1971) methods; distances were estimated by the method of Jukes \& Cantor (1969) by using MEGA version 3.0 (Kumar et al., 2004). The resultant tree topologies were evaluated by bootstrap analysis (Felsenstein, 1985) based on 1000 resampled datasets. DNA G $+\mathrm{C}$ contents were determined by HPLC, following hydrolysis, as described by Tamaoka \& Komagata (1984), and non-methylated $\lambda$ DNA (Sigma) was used as a standard. DNA-DNA hybridization was performed fluorometrically (Ezaki et al., 1989) by using DNA probes labelled with photobiotin (A1935; Sigma) and 96-well microdilution plates (Greiner Bio-One) at $50{ }^{\circ} \mathrm{C}$. 
The novel Halomonas strains formed visible colonies (about $2 \mathrm{~mm}$ in diameter) on solid $\mathrm{MH}$ medium at $30{ }^{\circ} \mathrm{C}$ within $48 \mathrm{~h}$. Good growth occurred at temperatures ranging from 20 to $35{ }^{\circ} \mathrm{C}$. Colonies were cream-coloured, translucent and circular with entire edges. Cells were aerobic, Gram-negative, motile and non-spore-forming rods.

The almost-complete 16S rRNA gene sequences (approx. $1500 \mathrm{nt}$ ) of the 14 isolates were determined and compared with those of existing species within the family Halomonadaceae. Strains S18214 ${ }^{\mathrm{T}}, \quad \mathrm{F} 22135, \quad \mathrm{~F} 22157$, F22171, H35115, T49407, T68674 and T68679, which shared $99.7-100.0 \%$ sequence similarity with each other and clustered as group I, showed the highest similarities to strain $\mathrm{W} 1025^{\mathrm{T}}$, strain $\mathrm{T} 68687^{\mathrm{T}}, H$. magadiensis $21 \mathrm{MI}^{\mathrm{T}}, H$. aquamarina DSM $30161^{\mathrm{T}}, H$. axialensis $\mathrm{Althf}^{\mathrm{T}}$ and $H$. meridiana DSM $5425^{\mathrm{T}}(99.4,99.0,98.2,98.0,98.0$ and $97.9 \%$, respectively). Strains $\mathrm{W} 1025^{\mathrm{T}}$, W1017 and W1023, which shared $99.9-100.0 \%$ similarity with each other and clustered as group II, showed the highest similarities to strain $\mathrm{T} 68687^{\mathrm{T}}$, strain $\mathrm{S} 18214^{\mathrm{T}}, H$. magadiensis $21 \mathrm{MI}^{\mathrm{T}}, H$. aquamarina DSM $30161^{\mathrm{T}}, H$. axialensis $\mathrm{Althf}^{\mathrm{T}}$ and $H$. meridiana DSM $5425^{\mathrm{T}}(99.5,99.4,98.6,98.5,98.5$ and $98.4 \%$, respectively). Strains $\mathrm{T} 68687^{\mathrm{T}}$, W1012 and W1019, which shared $99.9-100.0 \%$ similarity with each other and clustered as group III, showed the highest similarities to strain $\mathrm{W} 1025^{\mathrm{T}}$, strain $\mathrm{S} 18214^{\mathrm{T}}, H$. magadiensis $21 \mathrm{MI}^{\mathrm{T}}, H$. aquamarina DSM $30161^{\mathrm{T}}, H$. axialensis $\mathrm{Althf}^{\mathrm{T}}$ and $H$. meridiana DSM $5425^{\mathrm{T}}(99.5,99.0,98.9,98.5,98.5$ and $98.5 \%$, respectively). The 14 strains occupied three distinct positions among members of Halomonas rRNA group 2 (Arahal et al., 2002) and formed a stable branch with $H$. magadiensis, $H$. aquamarina, $H$. axialensis and $H$. meridiana in the phylogenetic tree (Fig. 1). An extended version of the $16 \mathrm{~S}$ rRNA gene phylogenetic tree, including all recognized species of the genus Halomonas, is available as Supplementary Fig. S1 in IJSEM Online.

DNA-DNA hybridization tests were performed among the novel Halomonas strains and related taxa to confirm the taxonomic status of the novel isolates. According to the DNA-DNA hybridization levels (see Supplementary Table S1 in IJSEM Online), members of group I shared $90-95 \%$

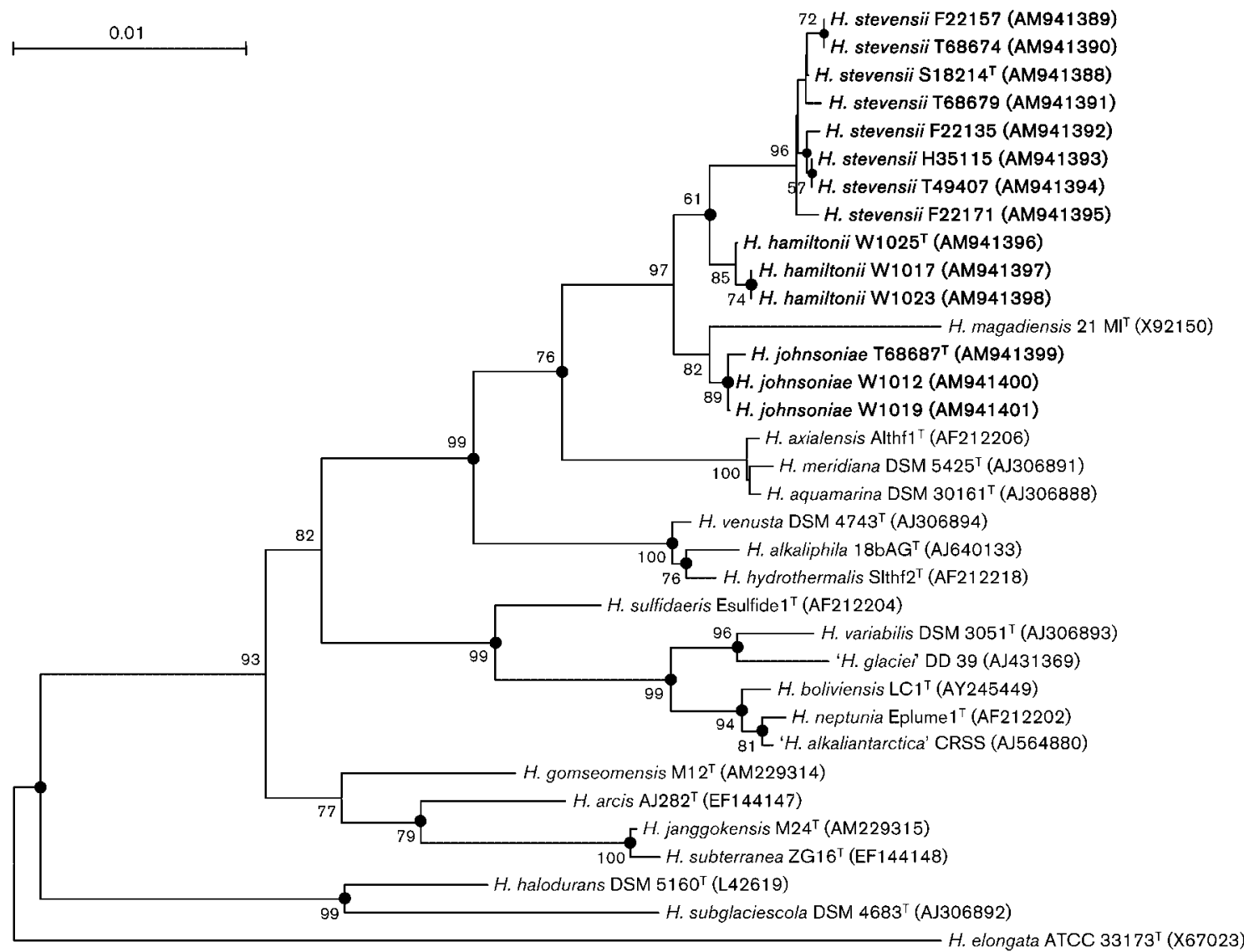

Fig. 1. Phylogenetic tree based on $16 \mathrm{~S}$ rRNA gene sequences constructed according to the neighbour-joining method showing the positions of the novel Halomonas strains among members of Halomonas rRNA group 2 (Arahal et al., 2002). Filled circles indicate branches that were also found with the maximum-parsimony treeing algorithm. Numbers at branch points refer to bootstrap percentages (from 1000 resamplings; only values $\geqslant 50 \%$ are shown). Bar, 1 substitution per 100 nt positions. 
Table 1. Differential characteristics of the novel strains and closely related type strains of the genus Halomonas

Species/strains: 1 , H. stevensii sp. nov. $(n=8) ; 2$, H. hamiltonii sp. nov. $(n=3) ; 3$, H. johnsoniae sp. nov. $(n=3) ; 4$, H. magadiensis KCTC $22195^{\mathrm{T}}$; 5 , H. aquamarina KCTC $22193^{\mathrm{T}}$; 6, H. axialensis KCTC $22194^{\mathrm{T}}$; 7, H. meridiana KCTC $22196^{\mathrm{T}}$. $n$, Number of strains tested; +, positive; -, negative; $\mathrm{V}$, variable; data in parentheses are for the type strain.

\begin{tabular}{|c|c|c|c|c|c|c|c|}
\hline Characteristic & 1 & 2 & 3 & 4 & 5 & 6 & 7 \\
\hline Pigmentation & Cream & Cream & Cream & Cream & Cream & Cream & White \\
\hline Cell length $(\mu \mathrm{m})$ & $2.0-3.0$ & $2.0-3.0$ & $1.5-4.0$ & $4.0-6.0^{*}$ & $4.0-6.0^{*}$ & $2.0-3.0 \dagger$ & $1.5-4.0^{*}$ \\
\hline Cell width $(\mu \mathrm{m})$ & $0.9-1.1$ & $0.9-1.0$ & $0.7-0.9$ & $0.6-0.8^{\star}$ & $0.4-0.8^{\star}$ & $0.9-1.0 \dagger$ & $0.6-1.0^{\star}$ \\
\hline Flagella arrangement $\ddagger$ & $\mathrm{Pe}$ & $\mathrm{L}$ & L-P & $\mathrm{Pe}$ & $\mathrm{Pe}^{*}$ & $\mathrm{Pe} \dagger$ & $\mathrm{L}^{*}$ \\
\hline \multicolumn{8}{|l|}{ Salt tolerance (\% total salts): } \\
\hline Range & $0-20$ & $0-20$ & $0-20$ & $0-20 \S$ & $0.5-20 \S$ & $0.5-24 \dagger$ & $0-20 \S$ \\
\hline Optimum & $3.0-7.5$ & $5.0-7.5$ & $0-5$ & $0-7 \S$ & $7.5-10.0 \$$ & $4 \dagger$ & $1-3 \S$ \\
\hline \multicolumn{8}{|l|}{ Temperature tolerance $\left({ }^{\circ} \mathrm{C}\right)$ : } \\
\hline Range & $10-40$ & $10-40$ & $10-40$ & $20-50 \dagger$ & $5-40 \dagger$ & -1 to $35 \dagger$ & -5 to $45 \dagger$ \\
\hline Optimum & $30-35$ & $30-35$ & $30-35$ & $37 \dagger$ & $20-25 \dagger$ & $30 \dagger$ & $28-40 \dagger$ \\
\hline \multicolumn{8}{|l|}{ pH tolerance: } \\
\hline Range & $7-11$ & $6-10$ & $7-10$ & $5-11 \S$ & $5-10 \$$ & $5-12 \dagger$ & $5-10 \$$ \\
\hline Optimum & $8-9$ & $8-9$ & $8-9$ & $9-10$ & $7-8$ & $7-8 \dagger$ & $7-8$ \\
\hline Voges-Proskauer test & - & + & - & - & - & - & - \\
\hline $\mathrm{H}_{2} \mathrm{~S}$ production & + & + & + & + & - & - & + \\
\hline Nitrate reduction & - & - & + & + & + & + & - \\
\hline Urease & + & $\mathrm{v}(-)$ & - & + & - & - & + \\
\hline Growth on cetrimide agar & $\mathrm{v}(+)$ & + & $\mathrm{v}(-)$ & - & - & + & - \\
\hline \multicolumn{8}{|l|}{ Respiration on: } \\
\hline Nitrate & - & - & - & - & - & + & - \\
\hline Nitrite & - & - & - & - & - & + & - \\
\hline \multicolumn{8}{|l|}{ Acid production from: } \\
\hline L-Arabinose & - & + & - & + & - & - & + \\
\hline D-Fucose & - & + & - & + & - & - & - \\
\hline D-Galactose & - & + & - & + & - & - & + \\
\hline Maltose & + & - & - & + & - & - & + \\
\hline Methyl $\alpha$-D-glucoside & + & + & - & + & + & - & - \\
\hline Glycerol & + & - & + & + & + & - & - \\
\hline Inositol & + & - & - & - & - & - & - \\
\hline D-Mannitol & - & - & + & + & + & - & + \\
\hline D-Sorbitol & - & - & - & + & + & - & + \\
\hline \multicolumn{8}{|l|}{ Growth on: } \\
\hline L-Arabinose & - & - & - & + & + & + & - \\
\hline D-Fucose & - & - & - & + & - & - & + \\
\hline D-Galactose & - & + & - & + & - & - & + \\
\hline Lactose & - & - & - & + & + & - & - \\
\hline Melezitose & - & + & + & - & + & - & + \\
\hline Amygdalin & - & - & - & + & - & - & + \\
\hline Glycogen & - & - & - & - & + & + & + \\
\hline Starch & $\mathrm{v}(+)$ & - & - & + & + & - & - \\
\hline Dulcitol & - & - & - & + & - & - & + \\
\hline myo-Inositol & + & - & - & + & + & - & + \\
\hline D-Mannitol & - & + & + & + & + & - & + \\
\hline D-Sorbitol & - & + & + & + & - & - & - \\
\hline Adipate & - & + & - & + & - & + & + \\
\hline 4-Hydroxybenzoate & - & + & + & + & - & - & - \\
\hline Malonate & - & + & - & - & + & - & - \\
\hline L-Cysteine & + & - & - & - & - & - & - \\
\hline DL-Isoleucine & - & - & + & + & + & + & + \\
\hline L-Lysine & - & + & - & + & + & - & + \\
\hline L-Methionine & + & - & - & + & - & - & - \\
\hline L-Valine & + & - & + & + & - & - & + \\
\hline
\end{tabular}


Table 1. cont.

\begin{tabular}{|c|c|c|c|c|c|c|c|}
\hline Characteristic & 1 & 2 & 3 & 4 & 5 & 6 & 7 \\
\hline \multicolumn{8}{|l|}{ Hydrolysis of: } \\
\hline DNA & - & - & - & + & + & - & - \\
\hline L-Valyl 2-naphthylamide & - & - & - & + & + & + & + \\
\hline \multicolumn{8}{|l|}{ Susceptibility to: } \\
\hline Chloramphenicol & + & - & $\mathrm{V}(-)$ & + & + & + & + \\
\hline Tetracycline & + & + & + & - & - & - & - \\
\hline Trimethoprim/sulfamethoxazole & - & - & - & + & + & + & + \\
\hline Vancomycin & $\mathrm{v}(+)$ & - & - & - & - & - & - \\
\hline DNA G + C content $(\mathrm{mol} \%)$ & $61.0-63.2$ & $63.0-64.6$ & $64.4-65.2$ & 62.2 & $58.0 \dagger$ & $57.6 \dagger$ & $59.5 \dagger$ \\
\hline
\end{tabular}

${ }^{\star}$ Data from Arahal et al. (2002).

$\dagger$ Data from Kaye et al. (2004).

¥L, Lateral; L-P, lateral/polar; Pe, peritrichous.

§Data from Mata et al. (2002).

relatedness and strain $\mathrm{S} 18214^{\mathrm{T}}$, the type of group I, showed $17-42 \%$ hybridization with strain $\mathrm{W} 1025^{\mathrm{T}}$, strain $\mathrm{T} 68687^{\mathrm{T}}$, and the type strains of $H$. magadiensis, $H$. aquamarina, $H$. axialensis and $H$. meridiana. Members of group II shared $88-90 \%$ relatedness and strain $\mathrm{W} 1025^{\mathrm{T}}$, the type of group II, showed $35-52 \%$ hybridization with strain $\mathrm{T} 68687^{\mathrm{T}}$, strain $S 18214^{\mathrm{T}}$, and the type strains of $H$. magadiensis, $H$. aquamarina, $H$. axialensis and $H$. meridiana. Members of group III shared $90-93 \%$ relatedness and strain T68687 ${ }^{\mathrm{T}}$, the type of group III, showed $32-52 \%$ hybridization with strain $\mathrm{W} 1025^{\mathrm{T}}$, strain $\mathrm{S} 18214^{\mathrm{T}}$, and the type strains of $H$. magadiensis, $H$. aquamarina, $H$. axialensis and $H$. meridiana. Consequently, DNA-DNA hybridization results confirmed the proposal of three novel Halomonas species (Wayne et al., 1987).

The physiological, biochemical and chemotaxonomic characteristics of the novel Halomonas species are given in the species descriptions and those that distinguish them from related taxa and from each other are listed in Table 1. The novel Halomonas species could be distinguished from related taxa by differences in cell morphology, cell growth ranges, hydrolysis of tyrosine and L-valyl 2-naphthylamide and susceptibility to tetracycline and trimethoprim/sulfamethoxazole, as well as by differences in acid production and substrate utilization profiles. Furthermore, significant differences in Voges-Proskauer test results, nitrate reduction, urease activity, acid production from L-arabinose, Dfucose, D-galactose, maltose, inositol and D-mannitol, growth on D-galactose, starch, myo-inositol, adipate, malonate, L-cysteine, DL-isoleucine, L-lysine and L-methionine, and susceptibility to chloramphenicol, neomycin and vancomycin supported the proposal of three novel species of the genus Halomonas.

The fatty acid profiles of the novel Halomonas species were similar to those of related taxa; the fatty acids $\mathrm{C}_{18: 1} \omega 7 c$ and
$\mathrm{C}_{16: 0}$ were predominant. However, they showed slight differences, e.g. higher amounts of $\mathrm{C}_{18: 1} \omega 7 c$ and the absence of $\mathrm{C}_{17: 0}$ cyclo and $\mathrm{C}_{19: 0}$ cyclo $\omega 8 c$, to related taxa except $H$. magadiensis. When cells were grown on media with different $\mathrm{NaCl}$ concentrations, i.e. TSA and TSA with $5 \%(\mathrm{w} / \mathrm{v}) \mathrm{NaCl}$, no significant change in fatty acid composition was observed for all tested strains. Detailed fatty acid compositions are shown in Table 2 and Supplementary Table S2 (available in IJSEM Online).

Combined phenotypic and genotypic data support the proposal that the 14 strains represent three novel species in the genus Halomonas, for which the names Halomonas stevensii sp. nov., Halomonas hamiltonii sp. nov. and Halomonas johnsoniae sp. nov. are proposed.

\section{Description of Halomonas stevensii sp. nov.}

Halomonas stevensii (ste.ven'si.i. N.L. gen. n. stevensii of Stevens, named after Dr David A. Stevens, a physician/ epidemiologist who isolated and characterized the first strains).

Cells are aerobic, Gram-stain-negative and non-sporeforming rods $(0.9-1.1 \times 2.0-3.0 \mu \mathrm{m})$. Cells are motile with peritrichous flagella. PHB is accumulated. EPS is not produced. Colonies are cream-coloured, smooth, translucent and circular with entire edges. Catalase- and oxidase-positive. Growth occurs at $10-40{ }^{\circ} \mathrm{C}$ (optimum $30-35{ }^{\circ} \mathrm{C}$ ) and at $\mathrm{pH} 7-11$ (optimum $\mathrm{pH}$ 8-9). Growth occurs at sea-salt concentrations of $0-20 \% \quad(w / w)$ (optimum 3.0-7.5\%, w/v). Growth is observed on MacConkey agar. Anaerobic growth is not observed on solid $\mathrm{MH}$ medium. Indole is not produced. $\mathrm{H}_{2} \mathrm{~S}$ is produced from L-cysteine. Nitrate is not reduced. Selenite is reduced. Methyl red and Voges-Proskauer tests are negative. Utilization of glucose is oxidative. Gluconate is 
Table 2. Cellular fatty acids of the novel strains and closely related type strains of the genus Halomonas grown on TSA

Species/strains: 1 , H. stevensii sp. nov. ( $n=8) ; 2$, H. hamiltonii sp. nov. $(n=3) ; 3$, H. johnsoniae sp. nov. $(n=3) ; 4, H$. magadiensis KCTC $22195^{\mathrm{T}}$; 5 , H. aquamarina KCTC $22193^{\mathrm{T}} ; 6$, H. axialensis KCTC $22194^{\mathrm{T}} ; 7$, H. meridiana KCTC $22196^{\mathrm{T}}$. $n$, Number of strains tested. Fatty acids are listed using standard abbreviations (number of carbon atoms: number of double bonds). Means \pm SD are given where appropriate. ND, Not detected.

\begin{tabular}{|c|c|c|c|c|c|c|c|}
\hline Fatty acid & 1 & 2 & 3 & 4 & 5 & 6 & 7 \\
\hline $\mathrm{C}_{10: 0}$ & $1.5 \pm 0.2$ & $1.1 \pm 0.1$ & $1.6 \pm 0.1$ & 1.6 & 2.3 & 0.5 & 0.5 \\
\hline$C_{12: 0}$ & ND & $0.7 \pm 0.1$ & $0.5 \pm 0.1$ & 0.7 & 1.2 & 1.0 & 1.0 \\
\hline $\mathrm{C}_{12: 0} 3-\mathrm{OH}$ & $7.7 \pm 0.1$ & $8.7 \pm 0.4$ & $7.4 \pm 0.1$ & 9.5 & 10.3 & 11.1 & 6.3 \\
\hline $\mathrm{C}_{14: 0}$ & $3.6 \pm 0.1$ & $3.7 \pm 0.0$ & $3.5 \pm 0.1$ & 4.3 & 4.5 & 3.7 & 3.3 \\
\hline Summed feature $4^{*}$ & $6.5 \pm 0.1$ & $7.0 \pm 0.1$ & $6.1 \pm 0.1$ & 7.2 & 10.1 & 9.6 & 10.4 \\
\hline $\mathrm{C}_{16: 0}$ & $13.5 \pm 0.3$ & $14.1 \pm 0.6$ & $13.7 \pm 0.4$ & 12.7 & 17.1 & 14.6 & 14.8 \\
\hline $\mathrm{C}_{17: 0}$ cyclo & ND & $\mathrm{ND}$ & $\mathrm{ND}$ & $\mathrm{ND}$ & 1.7 & 0.3 & 0.7 \\
\hline $\mathrm{C}_{18: 1} \omega 7 c$ & $65.9 \pm 0.5$ & $63.6 \pm 1.0$ & $66.0 \pm 0.3$ & 62.6 & 48.5 & 57.9 & 60.5 \\
\hline $\mathrm{C}_{18: 0}$ & $0.5 \pm 0.1$ & $0.3 \pm 0.1$ & $1.2 \pm 0.2$ & 0.4 & 0.5 & 0.4 & 0.2 \\
\hline 11-Methyl $C_{18: 1} \omega 7 c$ & $0.8 \pm 0.1$ & $0.8 \pm 0.1$ & ND & 0.8 & ND & ND & $\mathrm{ND}$ \\
\hline $\mathrm{C}_{19: 0}$ cyclo $\omega 8 \mathrm{c}$ & ND & ND & ND & $\mathrm{ND}$ & 3.7 & 0.8 & 2.2 \\
\hline
\end{tabular}

${ }^{\star}$ Summed feature 4 contains $\mathrm{C}_{16: 1} \omega 7 c$ and/or iso- $\mathrm{C}_{15: 0} 2-\mathrm{OH}$.

oxidized. Respiration on nitrate, nitrite or fumarate is negative. Tween 20, Tween 80 and tyrosine are hydrolysed, but aesculin, casein, DNA, gelatin, starch and $o$-nitrophenyl- $\beta$-D-galactopyranoside are not. Blood is not haemolysed. Urease is produced, but arginine dihydrolase, lysine decarboxylase, ornithine decarboxylase, phenylalanine deaminase, $\beta$-galactosidase, lecithinase and phosphatase are not. Acetate, citrate, ethanol, D-fructose, fumarate, gluconate, D-glucose, glycerol, myo-inositol, malate, maltose, propionate, succinate, sucrose and trehalose are utilized as sole sources of carbon and energy, but adipate, adonitol, aesculin, amygdalin, L-arabinose, cellobiose, dulcitol, formate, D-fucose, D-galactose, glycogen, 3-hydroxybenzoate, 4-hydroxybenzoate, lactose, malonate, D-mannitol, Dmannose, melezitose, raffinose, L-rhamnose, D-ribose, Dsalicin, sorbitol and D-xylose are not. L-Alanine, L-cysteine, L-proline, L-serine, L-methionine and L-valine are utilized as sole sources of carbon, nitrogen and energy, but Lhistidine, DL-isoleucine and L-lysine are not. In the API $50 \mathrm{CH}$ gallery, acid is produced from D-fructose, D-glucose, maltose, glycerol, methyl $\alpha$-D-glucoside, sucrose, trehalose and turanose, but not from $N$-acetylglucosamine, aesculin, D-adonitol, amygdalin, D-arabinose, L-arabinose, D-arabitol, L-arabitol, arbutin, cellobiose, dulcitol, erythritol, Dfucose, L-fucose, D-galactose, gentiobiose, gluconate, glycogen, inositol, inulin, 2-ketogluconate, 5-ketogluconate, lactose, D-lyxose, D-mannitol, D-mannose, melezitose, melibiose, methyl $\alpha$-D-mannoside, methyl $\beta$-D-xyloside, raffinose, L-rhamnose, D-ribose, D-salicin, D-sorbitol, Lsorbose, starch, D-tagatose, xylitol, D-xylose or L-xylose. According to results from API ZYM tests, L-leucyl 2naphthylamide, 2-naphthyl butyrate and 2-naphthyl $\alpha$-Dglucopyranoside are hydrolysed, but $N$-benzoyl-DL-arginine 2-naphthylamide, 6-bromo-2-naphthyl $\alpha$-D-galactopyranoside, 6-bromo-2-naphthyl $\beta$-D-glucopyranoside, 6bromo-2-naphthyl $\alpha$-D-mannopyranoside, L-cystyl 2- naphthylamide, $\quad N$-glutaryl-phenylalanine 2-naphthylamide, naphthol-AS-BI- $\beta$-D-glucuronide, naphthol-ASBI-phosphate, 1 -naphthyl $N$-acetyl- $\beta$-D-glucosaminide, 2-naphthyl caprylate, 2-naphthyl $\alpha$-L-fucopyranoside, 2 naphthyl $\beta$-D-galactopyranoside, 2-naphthyl myristate, 2naphthyl phosphate (pH 5.4), 2-naphthyl phosphate (pH 8.5) and L-valyl 2-naphthylamide are not. Susceptible to amoxicillin, ampicillin, carbenicillin, cefotaxime, cefoxitin, chloramphenicol, nalidixic acid, nitrofurantoin, penicillin $\mathrm{G}$, polymyxin $\mathrm{B}$, rifampicin, sulphamide, tetracycline and tobramycin. Resistant to kanamycin, streptomycin and trimethoprim/sulfamethoxazole. Susceptibility to erythromycin, neomycin and vancomycin is strain-dependent. The predominant quinone is ubiquinone Q-9; a small amount of Q-8 is also present. The fatty acids $\mathrm{C}_{18: 1} \omega 7 c$ and $\mathrm{C}_{16: 0}$ are predominant. The $\mathrm{G}+\mathrm{C}$ content of the DNA is $61.0-63.2 \mathrm{~mol} \%$.

The type strain, S18214 ${ }^{\mathrm{T}}\left(=\mathrm{KCTC} 22148^{\mathrm{T}}=\mathrm{DSM} 21198^{\mathrm{T}}\right)$, was isolated from blood of a renal care patient. The DNA $\mathrm{G}+\mathrm{C}$ content of the type strain is $62.0 \mathrm{~mol} \%$.

\section{Description of Halomonas hamiltonii sp. nov.}

Halomonas hamiltonii (ha.mil.to' ni.i. N.L. gen. n. hamiltonii of Hamilton, named after Dr John R. Hamilton, a microbiologist who isolated and characterized the first strains).

Cells are aerobic, Gram-stain-negative and non-sporeforming rods $(0.9-1.0 \times 2.0-3.0 \mu \mathrm{m})$. Cells are motile with lateral flagella. PHB is accumulated. EPS is not produced. Colonies are cream-coloured, smooth, translucent and circular with entire edges. Catalase- and oxidase-positive. Growth occurs at $10-40{ }^{\circ} \mathrm{C}$ (optimum $30-35{ }^{\circ} \mathrm{C}$ ) and at pH 6-10 (optimum pH 8-9). Growth occurs at sea-salt concentrations of $0-20 \%(\mathrm{w} / \mathrm{w})$ (optimum $5.0-7.5 \%$, w/ 
v). Good growth is observed on MacConkey agar. Anaerobic growth is not observed on solid $\mathrm{MH}$ medium. Indole is not produced. $\mathrm{H}_{2} \mathrm{~S}$ is produced from L-cysteine. Nitrate is not reduced. Selenite is reduced. Methyl red test is negative, but Voges-Proskauer test is positive. Utilization of glucose is oxidative. Gluconate is oxidized. Respiration on nitrate, nitrite or fumarate is negative. Tween 20, Tween 80 and tyrosine are hydrolysed, but aesculin, casein, DNA, gelatin, starch and $o$-nitrophenyl- $\beta$ D-galactopyranoside are not. Blood is not haemolysed. Arginine dihydrolase, lysine decarboxylase, ornithine decarboxylase, phenylalanine deaminase, $\beta$-galactosidase, lecithinase and phosphatase are not produced. Acetate, adipate, citrate, ethanol, D-fructose, fumarate, D-galactose, gluconate, D-glucose, glycerol, 4-hydroxybenzoate, malate, malonate, maltose, D-mannitol, melezitose, propionate, sorbitol, succinate, sucrose and trehalose are utilized as sole sources of carbon and energy, but adonitol, aesculin, amygdalin, L-arabinose, cellobiose, dulcitol, formate, Dfucose, glycogen, 3-hydroxybenzoate, myo-inositol, lactose, D-mannose, raffinose, L-rhamnose, D-ribose, D-salicin, starch and D-xylose are not. L-Alanine, L-lysine, L-proline and L-serine are utilized as sole sources of carbon, nitrogen and energy, but L-cysteine, L-histidine, DL-isoleucine, Lmethionine and L-valine are not. In the API 50CH gallery, acid is produced from L-arabinose, D-fructose, D-fucose, Dgalactose, D-glucose, methyl $\alpha$-D-glucoside, sucrose, trehalose and turanose, but not from $N$-acetylglucosamine, aesculin, D-adonitol, amygdalin, D-arabinose, D-arabitol, Larabitol, arbutin, cellobiose, dulcitol, erythritol, L-fucose, gentiobiose, gluconate, glycerol, glycogen, inositol, inulin, 2-ketogluconate, 5-ketogluconate, lactose, D-lyxose, maltose, D-mannitol, D-mannose, melezitose, melibiose, methyl $\alpha$-D-mannoside, methyl $\beta$-D-xyloside, raffinose, L-rhamnose, D-ribose, D-salicin, D-sorbitol, L-sorbose, starch, Dtagatose, xylitol, D-xylose or L-xylose. According to results from API ZYM tests, L-leucyl 2-naphthylamide, 2-naphthyl butyrate and 2-naphthyl $\alpha$-D-glucopyranoside are hydrolysed, but $N$-benzoyl-DL-arginine 2-naphthylamide, 6bromo-2-naphthyl $\alpha$-D-galactopyranoside, 6-bromo-2naphthyl $\beta$-D-glucopyranoside, 6-bromo-2-naphthyl $\alpha$-Dmannopyranoside, L-cystyl 2-naphthylamide, $N$-glutarylphenylalanine 2-naphthylamide, naphthol-AS-BI- $\beta$-D-glucuronide, naphthol-AS-BI-phosphate, 1-naphthyl $\mathrm{N}$ acetyl- $\beta$-D-glucosaminide, 2-naphthyl caprylate, 2naphthyl $\alpha$-L-fucopyranoside, 2 -naphthyl $\beta$-D-galactopyranoside, 2-naphthyl myristate, 2-naphthyl phosphate (pH 5.4), 2-naphthyl phosphate ( $\mathrm{pH} 8.5)$ and L-valyl 2naphthylamide are not. Susceptible to amoxicillin, ampicillin, carbenicillin, cefotaxime, cefoxitin, nalidixic acid, neomycin, nitrofurantoin, penicillin G, polymyxin B, rifampicin, sulphamide, tetracycline and tobramycin. Resistant to chloramphenicol, erythromycin, kanamycin, streptomycin, trimethoprim/sulfamethoxazole and vancomycin. The predominant quinone is ubiquinone Q-9; a small amount of Q-8 is also present. The fatty acids $\mathrm{C}_{18: 1} \omega 7 c$ and $\mathrm{C}_{16: 0}$ are predominant. The $\mathrm{G}+\mathrm{C}$ content of the DNA is $63.0-64.6 \mathrm{~mol} \%$.
The type strain, $\mathrm{W} 1025^{\mathrm{T}}\left(=\right.$ KCTC $\left.22154^{\mathrm{T}}=\mathrm{DSM} 21196^{\mathrm{T}}\right)$, was isolated from a dialysis machine drain. The DNA $\mathrm{G}+\mathrm{C}$ content of the type strain is $64.6 \mathrm{~mol} \%$.

\section{Description of Halomonas johnsoniae sp. nov.}

Halomonas johnsoniae (john.so'ni.ae. N.L. gen. n. johnsoniae of Johnson, named after Ms. Nancy Johnson, a registered nurse who isolated and characterized the first strains).

Cells are aerobic, Gram-stain-negative and non-sporeforming rods $(0.7-0.9 \times 1.5-4.0 \mu \mathrm{m})$. Cells are motile with lateral/polar flagella. PHB is accumulated. EPS is not produced. Colonies are cream-coloured, smooth, translucent and circular with entire edges. Catalase- and oxidase-positive. Growth occurs at $10-40{ }^{\circ} \mathrm{C}$ (optimum $30-35{ }^{\circ} \mathrm{C}$ ) and at $\mathrm{pH} 7-10$ (optimum $\mathrm{pH} 8-9$ ). Growth occurs at sea-salt concentrations of $0-20 \% \quad(w / w)$ (optimum $0-5 \%, w / v)$. Good growth is observed on MacConkey agar. Anaerobic growth is not observed on solid $\mathrm{MH}$ medium. Indole is not produced. $\mathrm{H}_{2} \mathrm{~S}$ is produced from L-cysteine. Nitrate is reduced, but nitrite is not. Selenite is reduced. Methyl red and VogesProskauer tests are negative. Utilization of glucose is oxidative. Gluconate is oxidized. Respiration on nitrate, nitrite or fumarate is negative. Tween 20, Tween 80 and tyrosine are hydrolysed, but aesculin, casein, DNA, gelatin, starch and $o$-nitrophenyl- $\beta$-D-galactopyranoside are not. Blood is not haemolysed. Arginine dihydrolase, lysine decarboxylase, ornithine decarboxylase, phenylalanine deaminase, $\beta$-galactosidase, lecithinase, phosphatase and urease are not produced. Acetate, citrate, ethanol, Dfructose, fumarate, gluconate, D-glucose, glycerol, 4hydroxybenzoate, malate, maltose, D-mannitol, melezitose, propionate, sorbitol, succinate, sucrose and trehalose are utilized as sole sources of carbon and energy, but adipate, adonitol, aesculin, amygdalin, L-arabinose, cellobiose, dulcitol, formate, D-fucose, D-galactose, glycogen, 3hydroxybenzoate, myo-inositol, lactose, malonate, D-mannose, raffinose, L-rhamnose, D-ribose, D-salicin, starch and D-xylose are not. L-Alanine, DL-isoleucine, L-proline, Lserine and L-valine are utilized as sole sources of carbon, nitrogen and energy, but L-cysteine, L-histidine, L-lysine and $\mathrm{L}$-methionine are not. In the API 50CH gallery, acid is produced from D-fructose, D-glucose, glycerol, D-mannitol, melezitose, sucrose, trehalose and turanose, but not from $\mathrm{N}$-acetylglucosamine, aesculin, D-adonitol, amygdalin, Darabinose, L-arabinose, D-arabitol, L-arabitol, arbutin, cellobiose, dulcitol, erythritol, D-fucose, L-fucose, D-galactose, gentiobiose, gluconate, glycogen, inositol, inulin, 2ketogluconate, 5-ketogluconate, lactose, D-lyxose, maltose, D-mannose, melibiose, methyl $\alpha$-D-glucoside, methyl $\alpha$-Dmannoside, methyl $\beta$-D-xyloside, raffinose, L-rhamnose, Dribose, D-salicin, D-sorbitol, L-sorbose, starch, D-tagatose, xylitol, D-xylose or L-xylose. According to results from API ZYM tests, L-leucyl 2-naphthylamide, 2-naphthyl butyrate and 2-naphthyl $\alpha$-D-glucopyranoside are hydrolysed, but 
$\mathrm{N}$-benzoyl-DL-arginine 2-naphthylamide, 6-bromo-2naphthyl $\alpha$-D-galactopyranoside, 6-bromo-2-naphthyl $\beta$ D-glucopyranoside, 6-bromo-2-naphthyl $\alpha$-D-mannopyranoside, L-cystyl 2-naphthylamide, $N$-glutaryl-phenylalanine 2 -naphthylamide, naphthol-AS-BI- $\beta$-D-glucuronide, naphthol-AS-BI-phosphate, 1 -naphthyl $N$-acetyl- $\beta$-D-glucosaminide, 2-naphthyl caprylate, 2 -naphthyl $\alpha$-L-fucopyranoside, $\quad 2$-naphthyl $\quad \beta$-D-galactopyranoside, 2 -naphthyl myristate, 2-naphthyl phosphate ( $\mathrm{pH} 5.4$ ), 2-naphthyl phosphate ( $\mathrm{pH} 8.5)$ and L-valyl 2-naphthylamide are not. Susceptible to amoxicillin, ampicillin, carbenicillin, cefotaxime, cefoxitin, nalidixic acid, nitrofurantoin, polymyxin $\mathrm{B}$, rifampicin, sulphamide, tetracycline and tobramycin. Resistant to erythromycin, kanamycin, neomycin, streptomycin, trimethoprim/sulfamethoxazole and vancomycin. Susceptibility to chloramphenicol and penicillin G is strain-dependent. The predominant quinone is ubiquinone Q-9; a small amount of Q-8 is also present. The fatty acids $\mathrm{C}_{18: 1} \omega 7 c$ and $\mathrm{C}_{16: 0}$ are predominant. The $\mathrm{G}+\mathrm{C}$ content of the DNA is $64.4-65.2 \mathrm{~mol} \%$.

The type strain, $668687^{\mathrm{T}}\left(=\right.$ KCTC $\left.22157^{\mathrm{T}}=\mathrm{DSM} 21197^{\mathrm{T}}\right)$, was isolated from a waste handling option port of a dialysis machine. The DNA $\mathrm{G}+\mathrm{C}$ content of the type strain is $64.4 \mathrm{~mol} \%$.

\section{Acknowledgements}

This work was supported by a grant from the KRIBB Research Initiative Program and by a grant, M10437010001, from the Ministry of Education, Science and Technology (MEST) of the Republic of Korea.

\section{References}

Arahal, D. R. \& Ventosa, A. (2006). The family Halomonadaceae. In The Prokaryotes: a Handbook on the Biology of Bacteria, 3rd edn, vol. 6, pp. 811-835. Edited by M. Dworkin, S. Falkow, E. Rosenberg, K. H. Schleifer \& E. Stackebrandt. New York: Springer.

Arahal, D. R., Ludwig, W., Schleifer, K. H. \& Ventosa, A. (2002). Phylogeny of the family Halomonadaceae based on $23 \mathrm{~S}$ and $16 \mathrm{~S}$ rDNA sequence analyses. Int J Syst Evol Microbiol 52, 241-249.

Ben Ali Gam, Z., Abdelkafi, S., Casalot, L., Tholozan, J. L., Oueslati, R. \& Labat, M. (2007). Modicisalibacter tunisiensis gen. nov., sp. nov., an aerobic, moderately halophilic bacterium isolated from an oilfieldwater injection sample, and emended description of the family Halomonadaceae Franzmann et al. 1989 emend. Dobson and Franzmann 1996 emend. Ntougias et al. 2007. Int J Syst Evol Microbiol 57, 2307-2313.

Ezaki, T., Hashimoto, Y. \& Yabuuchi, E. (1989). Fluorometric deoxyribonucleic acid-deoxyribonucleic acid hybridization in microdilution wells as an alternative to membrane filter hybridization in which radioisotopes are used to determine genetic relatedness among bacterial strains. Int J Syst Bacteriol 39, 224-229.

Felsenstein, J. (1985). Confidence limits on phylogenies: an approach using the bootstrap. Evolution 39, 783-791.

Fitch, W. M. (1971). Toward defining the course of evolution: minimum change for a specific tree topology. Syst Zool 20, 406-416.

Franzmann, P. D., Wehmeyer, U. \& Stackebrandt, E. (1988), Halomonadaceae fam. nov., a new family of the class Proteobacteria to accommodate the genera Halomonas and Deleya. Syst Appl Microbiol 11, 16-19.

Gerhardt, P., Murray, R. G. E., Wood, W. A. \& Krieg, N. R. (editors) (1994). Methods for General and Molecular Bacteriology. Washington, DC: American Society for Microbiology.

Hall, T. A. (1999). BioEdit: a user-friendly biological sequence alignment editor and analysis program for Windows 95/98/NT. Nucleic Acids Symp Ser 41, 95-98.

Jukes, T. H. \& Cantor, C. R. (1969). Evolution of protein molecules. In Mammalian Protein Metabolism, vol. 3, pp. 21-132. Edited by H. N. Munro. New York: Academic Press.

Kämpfer, P. \& Kroppenstedt, R. M. (1996). Numerical analysis of fatty acid patterns of coryneform bacteria and related taxa. Can J Microbiol 42, 989-1005.

Kaye, J. Z., Márquez, M. C., Ventosa, A. \& Baross, J. A. (2004). Halomonas neptunia sp. nov., Halomonas sulfidaeris sp. nov., Halomonas axialensis sp. nov. and Halomonas hydrothermalis sp. nov.: halophilic bacteria isolated from deep-sea hydrothermal-vent environments. Int J Syst Evol Microbiol 54, 499-511.

Klatte, S., Rainey, F. A. \& Kroppenstedt, R. M. (1994). Transfer of Rhodococcus aichiensis Tsukamura 1982 and Nocardia amarae Lechevalier and Lechevalier 1974 to the genus Gordona as Gordona aichiensis comb. nov. and Gordona amarae comb. nov. Int J Syst Bacteriol 44, 769-773.

Kumar, S., Tamura, K. \& Nei, M. (2004). MEGA3: integrated software for molecular evolutionary genetics analysis and sequence alignment. Brief Bioinform 5, 150-163.

Mata, J. A., Martínez-Cánovas, J., Quesada, E. \& Béjar, V. (2002). A detailed phenotypic characterisation of the type strains of Halomonas species. Syst Appl Microbiol 25, 360-375.

McClung, L. S. \& Toabe, R. (1947). The egg yolk plate reaction for the presumptive diagnosis of Clostridium sporogenes and certain species of the gangrene and botulinum groups. J Bacteriol 53, 139-147.

NCCLS (2003). Performance Standards for Antimicrobial Disk Susceptibility Tests. Approved Standard, 8th edn. NCCLS document M2-A8 (ISBN 1-56238-485-6). Wayne, PA: National Committee for Clinical Laboratory Standards.

Ntougias, S., Zervakis, G. I. \& Fasseas, C. (2007). Halotalea alkalilenta gen. nov., sp. nov., a novel osmotolerant and alkalitolerant bacterium from alkaline olive mill wastes, and emended description of the family Halomonadaceae Franzmann et al. 1989, emend. Dobson and Franzmann 1996. Int J Syst Evol Microbiol 57, 1975-1983.

Ostle, A. G. \& Holt, J. G. (1982). Nile blue A as a fluorescent stain for poly- $\beta$-hydroxybutyrate. Appl Environ Microbiol 44, 238-241.

Peçonek, J., Gruber, C., Gallego, V., Ventosa, A., Busse, H.-J., Kämpfer, P., Radax, C. \& Stan-Lotter, H. (2006). Reclassification of Pseudomonas beijerinckii Hof 1935 as Chromohalobacter beijerinckii comb. nov., and emended description of the species. Int J Syst Evol Microbiol 56, 1953-1957.

Rainey, F. A., Ward-Rainey, N., Kroppenstedt, R. M. \& Stackebrandt, E. (1996). The genus Nocardiopsis represents a phylogenetically coherent taxon and a district actinomycete lineage: proposal of Nocardiopsaceae fam. nov. Int J Syst Bacteriol 46, 1088-1092.

Rodríguez-Valera, F., Ruiz-Berraquero, F. \& Ramos-Cormenzana, A. (1981). Characteristics of the heterotrophic bacterial population in hypersaline environments of different salt concentration. Microb Ecol 7, 235-243.

Romano, I., Giordano, A., Lama, L., Nicolaus, B. \& Gambacorta, A. (2005). Halomonas campaniensis sp. nov., a haloalkaliphilic bacterium isolated from a mineral pool of Campania Region, Italy. Syst Appl Microbiol 28, 610-618. 
Romano, I., Lama, L., Nicolaus, B., Poli, A., Gambacorta, A. \& Giordano, A. (2006). Halomonas alkaliphila sp. nov., a novel halotolerant alkaliphilic bacterium isolated from a salt pool in Campania (Italy). J Gen Appl Microbiol 52, 339-348.

Saitou, N. \& Nei, M. (1987). The neighbour-joining method: a new method for reconstructing phylogenetic trees. Mol Biol Evol 4, 406-425.

Sánchez-Porro, C., Tokunaga, H., Tokunaga, M. \& Ventosa, A. (2007). Chromohalobacter japonicus sp. nov., a moderately halophilic bacterium isolated from a Japanese salty food. Int J Syst Evol Microbiol 57, 2262-2266.

Sánchez-Porro, C., de la Haba, R. R., Soto-Ramírez, N., Márquez, M. C., Montalvo-Rodríguez, R. \& Ventosa, A. (2009). Description of Kushneria aurantia gen. nov., sp. nov., a novel member of the family Halomonadaceae, and a proposal for reclassification of Halomonas marisflavi as Kushneria marisflavi comb. nov., of Halomonas indalinina as Kushneria indalinina comb. nov. and of Halomonas avicenniae as Kushneria avicenniae comb. nov. Int J Syst Evol Microbiol 59, 397-405.

Sasser, M. (1990). Identification of bacteria by gas chromatography of cellular fatty acids, MIDI Technical Note 101. Newark, DE: MIDI Inc.

Shin, Y. K., Lee, J.-S., Chun, C. O., Kim, H.-J. \& Park, Y.-H. (1996). Isoprenoid quinone profiles of Leclercia adecarboxylata KCTC $1036^{\mathrm{T}}$. J Microbiol Biotechnol 6, 68-69.

Skerman, V. B. D. (1967). A Guide to the Identification of the Genera of Bacteria, 2nd edn. Baltimore: Williams \& Wilkins.
Stevens, D. A., Hamilton, J. R., Johnson, N., Kim, K. K. \& Lee, J. S. (2008). Halomonas $(\mathrm{H})$, newly recognized pathogen, causing infections and contamination in dialysis ctr. (DC); 3 new species. In Proceedings of the 48th Annual ICAAC/IDSA 46th Annual Meeting, abstract no. K-534, Washington, DC: American Society for Microbiology/Infectious Diseases Society of America.

Tamaoka, J. \& Komagata, K. (1984). Determination of DNA base composition by reversed-phase high-performance liquid chromatography. FEMS Microbiol Lett 25, 125-128.

Thompson, J. D., Gibson, T. J., Plewniak, F., Jeanmougin, F. \& Higgins, D. G. (1997). The CLUSTAL_X windows interface: flexible strategies for multiple sequence alignment aided by quality analysis tools. Nucleic Acids Res 25, 4876-4882.

Ventosa, A., Quesada, E., Rodriguez-Valera, F., Ruiz-Berraquero, F. \& Ramos-Cormenzana, A. (1982). Numerical taxonomy of moderately halophilic Gram-negative rods. J Gen Microbiol 128, 1959-1968.

Wayne, L. G., Brenner, D. J., Colwell, R. R., Grimont, P. A. D., Kandler, O., Krichevsky, M. I., Moore, L. H., Moore, W. E. C., Murray, R. G. E. \& other authors (1987). International Committee on Systematic Bacteriology. Report of the ad hoc committee on reconciliation of approaches to bacterial systematics. Int J Syst Bacteriol 37, 463-464.

Wu, G., Wu, X.-Q., Wang, Y.-N., Chi, C.-Q., Tang, Y.-O., Kida, K., Wu, X.-L. \& Luan, Z.-K. (2008). Halomonas daqingensis sp. nov., a moderately halophilic bacterium isolated from an oilfield soil. Int $J$ Syst Evol Microbiol 58, 2859-2865. 